\title{
EVOLUÇÃO DAS PERSPECTIVAS TEÓRICAS DO MARKETING E A ABORDAGEM DO MARKETING ESTRATÉGICO
}

\author{
EVOLUTION OF THEORETICAL PERSPECTIVES OF MARKETING AND THE STRATEGIC \\ MARKETING APPROACH
}

\author{
Amanda Regina Leite \\ Universidade de Passo Fundo, Passo Fundo, RS, Brasil. E-mail: amanda-rl@hotmail.com
}

\section{Maira Sgarbossa}

Universidade de Passo Fundo, Passo Fundo, RS, Brasil. E-mail: maira.sgarbossa@hotmail.com

\begin{abstract}
Resumo: $\mathrm{O}$ marketing associa-se aos conceitos de criatividade e inovação para alcançar as metas focadas em estratégia de sobrevivência, de antecipação de necessidades do mercado e na pesquisa de novas tecnologias para produtos e serviços. Para compreender melhor o Marketing, assim como a sua crescente importância dentro das organizaçóes, esta pesquisa apresenta uma sintetização de seu desenvolvimento histórico, desde a época em que ainda não era considerada uma área específica do conhecimento, até os dias de hoje. Contudo, este trabalho tem por objetivo apresentar a evolução das perspectivas do marketing e a abordagem do marketing estratégico. Dessa forma, apresenta-se o início da história do Marketing, onde se identificam as primeiras atividades desenvolvidas, antes somente uma questão de mercado. Mostra-se a relação da orientação para o mercado, às trocas transacionais e a emergência do marketing de relacionamento a partir das atividades diferenciadas. Ainda se apresenta a abordagem do marketing estratégico, por ser fundamental nas organizações. Por fim, são apresentadas as limitações e algumas sugestôes de estudos futuros e contribuiçôes de estudos dentro da área do marketing.
\end{abstract}

Palavras-chave Marketing; Perspectivas teóricas; Marketing estratégico.

\begin{abstract}
Marketing is associated with the concepts of creativity and innovation to achieve the goals focused on a survival strategy, anticipating market needs, and researching new technologies for products and services. In order to better understand Marketing, as well as its growing importance within organizations, this research presents a synthesis of its historical development, from the time when it was not yet considered a specific area of knowledge, until today. However, this work aims to present the evolution of marketing perspectives and the approach of strategic marketing. In this way, the beginning of the history of Marketing is presented, where the first activities developed are identified, before only a question of the market. The relationship between market orientation, transactional exchanges, and the emergence of relationship marketing from differentiated activities is shown. The strategic marketing approach is still presented, as it is fundamental in organizations. Finally, the limitations and some suggestions for future studies and contributions from studies within the marketing area are presented.
\end{abstract}

Keywords: Marketing; Theoretical perspectives of marketing; Strategic marketing. 


\section{Introdução}

Entre os anos de 1950 e 1970, quando o nível de desenvolvimento dos mercados era considerado baixo, o marketing foi determinante para o crescimento das empresas e dos mercados como um todo (Kumar, 2004). A partir dos anos de 1980 os mercados passaram a tornar-se mais complexos, e novos modelos de negócios e organizaçóes começaram a surgir, incluindo alianças estratégicas e redes de empresas (Webster, 1992). Diante desse contexto emergente dos mercados, nos anos de 1990 os 4Ps (produto, preço, promoçáa e praça), foram essenciais para o desenvolvimento das organizaçóes e segmentação de mercado, mas perderam sua força como composto estratégico (Day \& Montgomery, 1999; Kumar, 2004) desde então, as práticas de marketing têm objetivado encontrar formas de tornar suas açóes cada vez mais estratégicas junto a diretoria.

Em 1985 a American Marketing Association (AMA) considerava o marketing como o processo de planejamento e execução da concepçáo, fixaçáo de preços, promoçáo e distribuição de ideias, bens e serviços para criar intercâmbios que satisfizessem os objetivos dos indivíduos e organização (AMA, 1985), esta definição refletia a tendência transacional da teoria do marketing, que estava mais orientada para o produto e transação, do que para o cliente e a relação. Entretanto, ao longo dos anos o pensamento e a visão de marketing passaram por diversas atualizaçóes. Historicamente em grande parte, as teorias de marketing desenvolveram-se por meio dos mercados de consumo em massa (Antunes \& Rita, 2008). Nesse contexto, com o dinamismo dos mercados e as frequentes intercorrências dos ambientes internos e externos destaca-se cada vez mais o papel do marketing estratégico, primeiramente como uma ferramenta a ser utilizada pelos gestores no tratamento das informaçóes de mercado, com o objetivo de auxiliar na formação de estratégias frente ao marketing operacional (Drucker, 2011; Lamb, Hair \& Mcdaniel, 2008). Assim, verifica-se sua importância em todos os níveis da estrutura hierárquica de uma organização, sendo essencial que todas as unidades de negócios estejam alinhadas com a visão estratégica da organização (Drucker, 2011; Lamb, Hair \& Mcdaniel, 2008).

A disponibilidade de informaçóes e o uso de novas tecnologias possibilitaram às organizaçóes incorporar maior poder de produtividade elevando sua capacidade de oferta. Entretanto, o poder de consumo embora também tenha se ampliado com o aumento da população, de certa forma não tem a capacidade de suprir a oferta, provocando um desequilíbrio entre a demanda e a oferta. Este fato exige das organizaçóes o conhecimento das necessidades dos seus clientes. Desse modo, se faz necessário que as organizaçóes busquem meios que obtenham demandar as suas ofertas. Neste sentido, o Marketing Estratégico, desempenha papel fundamental de aproximação da organização com os consumidores (Sparemberger \& Zamberlan, 2008).

Em razão do marketing se desenvolver como uma grande área, foram necessários esforços para a compreensão conceitual geral desta área de conhecimento, com a finalidade de debater e delimitar, a partir de todo conhecimento empírico construído, a fim de que pudesse ser identificada a real razáo de que elementos discutidos em marketing efetivamente relacionam-se com o fenômeno e como eles podem irão auxiliar as práticas organizacionais (Englert; Frio; Saldanha \& Rossi, 2018). O marketing ocupa um espaço importante nas organizaçóes, por permitir estudos aprofundados de mercado, alavancar o crescimento organizacional, fidelizar clientes, alcançar a rentabilidade do negócio, atuar diretamente na inteligência estratégica e competitiva das empresas, gerando valor e elevando o volume de vendas. Assim, por esses e 
outros motivos, torna-se relevante estudar o tema. Desse modo, no que se refere as contribuiçôes teóricas, este estudo oferece à literatura na área de marketing oportunidades para ampliar sua compreensão, bem como enfatizar a necessidade de mais pesquisas sobre o tema, sobretudo no atual cenário pandêmico, onde as formas de consumir continuam, mas a distância, fazendo despertar a necessidade de novas e contínuas reflexôes sobre a formulação e implementação de estratégias de marketing.

Dado o exposto, tem-se como objetivo deste estudo apresentar a evolução das perspectivas do marketing ao longo do tempo em especial a abordagem do marketing estratégico. Para tanto, o artigo está organizado em quatro seçôes. Além desta introdução, apresenta-se os conceitos teóricos referente ao marketing e sua evolução, iniciando pelos conceitos de orientação para o mercado, passando pelas trocas transacionais, perspectivas do marketing de relacionamento, a interação do marketing em mercados consumidores (B2C) e organizacionais (B2B) e concluindo com os estudos que auferem atenção da área atualmente. Posteriormente, na terceira seção, ressalta-se a importância do marketing estratégico, seu papel junto a diretoria e no processo de tomada de decisão nas organizaçóes. Por fim são apresentadas as conclusões deste ensaio e as sugestóes para estudos futuros referentes as abordagens apresentadas.

\section{Evolução do marketing e marketing estratégico}

Nesta seção, se apresenta a evolução do marketing de acordo com as perspectivas teóricas desenvolvidas ao longo do tempo, bem como, se ressalta a importância do marketing estratégico para as organizações.

\subsection{Evolução do marketing e suas perspectivas teóricas}

Foi a partir do século XII que se deu o surgimento de uma nova base social entre os habitantes burgos, os quais dedicavam-se ao artesanato e faziam parte da classe média. Já no século XIII, conhecido como o período da "Escolástica" surgiram as primeiras universidades medievais, conhecidas por instituiçôes do saber, São Tomás de Aquino e seus seguidores contribuíram para o estudo dos consumidores, desenvolvendo o que provavelmente foi a primeira análise formal das motivaçôes dos consumidores (Ambler, 2004). Anos mais tarde, em 1970 com início do advento da Revolução Industrial na Inglaterra em 1970 e se estendeu por outros países europeus a partir de 1830, o pensamento principal estava em produzir com o menor custo possível, pois tudo o que fosse produzido era consumido (Rocha \& Christensen, 1999).

Nesse contexto histórico, o marketing como área de conhecimento surgiu no início do século XX em universidades norte-americanas. Sua emergência ocorreu em meio a dificuldades que empresas da época enfrentavam em relação aos processos de distribuição (Moretti, Oliveira \& Souza, 2018). Essas empresas identificaram que para ser mais competitivas nos mercados consumidores era imprescindível ser eficiente, para assim manter sua lucratividade (Bluter, 1914; Vargo \& Lusch, 2004). Ao longo da história, diferentes perspectivas foram dadas ao marketing, o qual passou por inúmeras transformaçóes de conceitos e pensamentos, mas ainda, em seu macroambiente aconteceram mudanças fundamentais cujas repercussóes ecoaram por décadas, sendo a economia global profundamente afetada (Sheth, Gardner \& Garrett, 1988; Vargo \& Lush, 2004; He \& Harris, 2020). 
Felton (1959) define que o marketing é um estado de espírito da empresa que consiste na integração e coordenação de todas as funçôes de marketing que, consequentemente fundem-se com todas as outras funçóes corporativas, pelo princípio básico de produzir o máximo retorno no longo prazo. O princípio básico do autor centra-se na integração das atividades e no estado de espírito característico. Por outra perspectiva, Kotler (2000) menciona que o marketing é atividade humana conduzida à satisfação de necessidade e desejos por meio de um processo de troca. Logo para McCarthy (1976), marketing é a execução das atividades que buscam concretizar os objetivos de uma organizaçáo, prevendo as necessidades do cliente e conduzindo um fluxo de bens e serviços para a satisfação dessas necessidades, a partir do produtor o cliente. De acordo com a AMA (2017), marketing é a atividade, conjunto de instituiçóes e processos para criar, comunicar, entregar e trocar, cujo objetivo centra-se em oferecer valor para clientes, parceiros e a sociedade em geral.

Dessa forma, o marketing pode ser considerado tão longevo quanto o comércio, sendo ele uma das atividades mais antigas da história da humanidade (Ambler, 2004). Segundo o autor, seu início se deu com as trocas comerciais que foram as primeiras formas de mercar. Simóes (1976) também menciona que se deve considerar que algumas das antigas civilizaçóes em XIX se sobressaíram na arte de mercar, como foi o caso dos Fenícios, que fizeram do comércio a própria razão de ser de suas atividades.

Entretanto, dentre as orientaçóes estratégicas do marketing, as quais são: voltada para o produto/ serviço, para as vendas, para o mercado e para o cliente, aquela voltada para o mercado foi considerada significante devido sua capacidade de produzir soluçôes que atendam as preferências dos clientes. Logo, a orientação para o mercado de certa forma, é considerada um sistema de inteligência (Kohli \& Jaworski, 1990; Narver \& Slater, 1990; Deshpandé, Farley \& Webster, 1993; Jaworski, Macinnis \& Kohli, 2002). Ainda, Narver e Slater (1990) definem a orientação para o mercado como uma cultura organizacional composta por três dimensôes: a orientação para o cliente, à orientação para o concorrente e a coordenação interfuncional, conforme apresentado na Figura 1.

Figura 1 - Orientação para Mercado

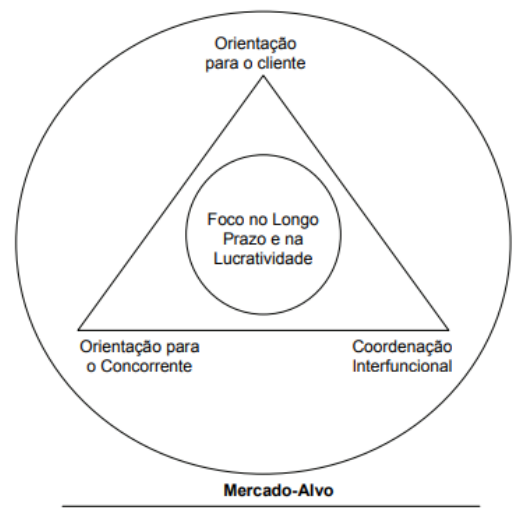

Fonte: Narver \& Slater (1990).

A orientação para o cliente envolve a compreensão de toda cadeia de valor e das necessidades dos clientes, assim como dos potenciais clientes, atuais e futuros, para que se possa decidir entre incrementar os benefícios percebidos com relação ao custo de obtenção pelo cliente ou diminuir o custo de obtenção com relação a esses benefícios, de forma que o cliente efetivamente obtenha sempre uma vantagem 
superior oferecida pela organização, superando as suas expectativas. A orientação para o concorrente significa que a organizaçáo deve conhecer as forças e fraquezas e ainda as capacidades e estratégias de curto prazo e longo prazo dos competidores e potenciais competidores do mercado alvo, para a superaçáo das expectativas dos clientes. E, por fim, a coordenação interfuncional requer que a cultura de entrega de valor ao cliente esteja impregnada em toda a rede de hierarquia interna envolvendo todas as atividades, funçóes e departamentos da organização, e não apenas aquela concentrada no departamento de marketing, de forma que, sistematicamente, as atividades estejam interligadas entre si, criando uma cadeia de valor interna voltada à entrega de valor superior ao cliente (Narver \& Slater, 1990).

Nessa concepção, Moreno, Rodrigues, Cantaleano, Kava \& Martins, (2016) apregoam que a cultura organizacional é mais eficaz e eficiente na promoção do comportamento necessário para criar maior valor para o cliente. Dessa forma, corrobora para um resultado positivo para a organização, visando à obtenção de vantagem competitiva sustentável de longo prazo, ensejando resultados positivos e por consequência, maior lucratividade.

Ademais, anos mais tarde emergiu o marketing de relacionamento (MR), pela falta de interatividade e preocupação com o cliente, uma vez que na fase marcada pela revolução industrial a preocupação estava apenas em elevar a produção. O MR tem suas bases nos trabalhos de Macneil $(1978,1980)$, que discutiam o impacto de contratos legais de longo prazo em relacionamentos de troca (Voss \& Voss, 1997). As primeiras discussóes acerca do relacionamento nos negócios emergiram e se desenvolveram a partir do âmbito de serviços, que fora apresentado pela primeira vez por Berry (1983). Os antecedentes originais desta abordagem encontram-se em duas linhas de investigação que se desenvolveram nos países escandinavos e no Norte da Europa. Essas duas linhas foram desenvolvidas pela escola nórdica de serviços, assim como pelo IMP Group (Industrial Marketing and Purchasing Group), escolas de pensamento que emergiram por volta de 1970 (Barakat, Lara \& Gosling, 2011).

Por mais que Berry em 1983 tenha formalizado o termo de marketing de relacionamento, a escola Nórdica e o IMP Group já trabalhavam neste sentido, mas fazendo uso de outros termos (Hunt, Arnett \& Madhavaram, 2006). Contudo, a relevância em estudar os relacionamentos foi aprofundada mais tarde por Gronröos (1990), Christopher, Payne e Ballantine (2004) e Bitner (1995) que se destacaram por suas contribuiçóes no âmbito de serviços, contribuindo para que os comerciantes e a indústria percebessem que os consumidores e seus comportamentos de compra estavam se alterando (Antunes \& Rita, 2008). A partir de então, emergiram outras linhas de investigação como aquela relacionada a mercados de consumo. Nela, é analisado o comportamento relacional do consumidor, destacando-se por suas contribuiçóes: Sheth e Parvatiyar (1995), Bagozzi (1995) e Peterson (1995). Logo, a linha do marketing de relacionamento, voltada aos canais de distribuição cuja observaçáo está no desenvolvimento de suas relaçôes, as contribuiçốes estão por Nevin (1995), Weitz e Jap (1995).

Nessa concepção, Antunes e Rita (2008) acrescem que a relação de interação entre mercados consumidores e industriais, antes distintas e não possíveis de serem tratadas da mesma forma, também foram observadas e apresentadas como prováveis. Desse modo, para melhor compreensão conceitual destes dois mercados, Churchill e Peter (2005) exemplificam a existência de dois tipos de clientes que participam de trocas comerciais: os compradores organizacionais e os consumidores. Os compradores organizacionais compram bens e serviços para empresas, órgãos governamentais e outras instituições, já os consumidores 
são pessoas que adquirem bens e serviços para seu próprio uso ou de outros. Diante disso, o autor adverte que o marketing é usado para desenvolver trocas que podem visar lucros ou não.

Muitas são as abordagens e estratégias existentes, tanto para o mercado consumidor quanto para o mercado organizacional. Nos mercados consumidores (B2C) o público alvo geralmente é maior e as exigências dos consumidores são menores. Ao longo dos anos este público foi tornando-se mais exigente e passou a auto dividir-se em faixas, ou níveis. Essa divisão é considerada relevante, pois auxiliam os profissionais de marketing na segmentação dos públicos e na criação de nichos específicos, aumentando a necessidade de maior personalização em seus produtos e serviços. Já em relação aos mercados consumidores, os pontos que mais desenvolveram-se foram aqueles voltados ao comportamento do consumidor e o processo de decisão de compra (Gruen, 1995; Korper \& Ellis, 2000; O’Malley \& Tynan, 2000).

Nos mercados industriais ou Business to Business (B2B) o público alvo é composto pelas partes envolvidas (fabricantes, comerciantes, varejistas e afins), como referem Lilien (2016) e Joshi e Dumbre (2017). Na maioria das vezes o público é mais restrito em quantidade de clientes, mas com alta exigência e elevado nível de conhecimento sobre o produto a ser adquirido, o que requer uma maior preparaçáo e comprometimento do vendedor. As transaçóes acontecem em unidades menores, a compra tende a ser mais direta e o consumidor é quem decide e direciona os rumos deste mercado (Gruen, 1995; Lilien, 2016). Assim, com o novo enfoque para o marketing de relacionamento e seu desenvolvimento nos mercados consumidores e industriais, teve sua ênfase reduzida em transaçóes de curto prazo, alargando seu foco em relacionamentos de longo prazo com o cliente (Hakansson 1982; Storbacka 1994).

Voltado para o cliente, o conceito de customer equity, assume que estes são ativos e possibilitam a empresa poder mensurar, gerenciar e maximizá-los. Assim os recursos alocados no marketing devem ser considerados investimentos que induzem mudanças comportamentais positivas em seus clientes, e não apenas se apresentam como um simples gasto (Blattberg; Deighton, 1996; Gupta, Lehmann \& Stuart, 2004). Diante desse contexto o marketing passou a ser criticado pois os investimentos com a área de marketing não eram evidentes em relação ao custo benefício. Foi então que em 1999, com o MSI/Workshop Conference Marketing Metrics (1999), que o desenvolvimento de formas de mensuração de métricas de marketing, definitivamente passou a fazer parte da agenda de pesquisa da área. Nessa conferência, os acadêmicos apresentaram trabalhos e perspectivas acerca do valor do cliente e da marca, métricas do mix de marketing, novas métricas financeiras e valoração do E-commerce (Grinberg \& Luce, 2000).

Desde então, o marketing vem voltando parte de sua atenção para o entendimento dos aspectos que influenciam o comportamento do cliente no momento da decisão de compra, considerando as modalidades de compra física ou virtual. As condutas, atitudes e decisóes podem ser explicados pelos valores pessoais intrínsecos das pessoas, que de acordo com Schwartz (1992) são consideradas metas desejáveis, atuando como princípios orientadores na vida das pessoas, expressando os objetivos que as motivam e as direcionam no caminho para atingi-los. Desse modo, a teoria dos valores pessoais se constitui em uma importante vertente de investigação que permite acessar os comportamentos de consumo e explicar elementos de interesse do marketing no âmbito acadêmico, como aplicado para pesquisas que envolvem os valores. Foram desenvolvidas diversas escalas para mensuração de valores dentre os quais, as mais conhecidas e utilizadas são: a Rokeach Value Survey (RVS) desenvolvida por Rokeach (1973), a Value Survey de Schwartz (1992;1994), a PVQ (40) de Schwartz et al. (2001) e a PVQ (21) de Schwartz (2006). 
Assim a teoria dos valores pessoais possui aspectos teóricos e metodológicos, desenvolvidos especificamente para finalidades de marketing.

Outros aspectos também estudados pelo marketing são a satisfação, recomendação e recompra. A satisfação desempenha um papel que reflete a resposta ao contentamento do consumidor e o julgamento de que uma característica do produto ou serviço ofereceu ou está oferecendo, seja ele em nível prazeroso de contentamento ao consumo, ou incluindo níveis maiores e/ou menores de regozijo (Oliver, 1997). Nesse sentido entende-se que quanto maior a satisfação, maior será a probabilidade de um mesmo cliente recomprar o mesmo produto e até mesmo recomendar o produto ou serviço de uma forma positiva para outras pessoas (Lobuono, Gosling, Gonçalves, \& Medeiros, 2016; Lübeck, Santini, Camargo \& Wanin, 2016; Mangini, Urdan \& Santos, 2017).

Contudo, nesse contexto evolucionário das perspectivas do marketing, a Figura 2 proposta por Kotler, Kartajaya e Setiawan (2010) mostra como a evolução do marketing se processou, acrescentando os focos que orientaram a reflexão sobre a disciplina, em cada década desde 1950.

Figura 2 - Evolução do Marketing a partir da década de 1950

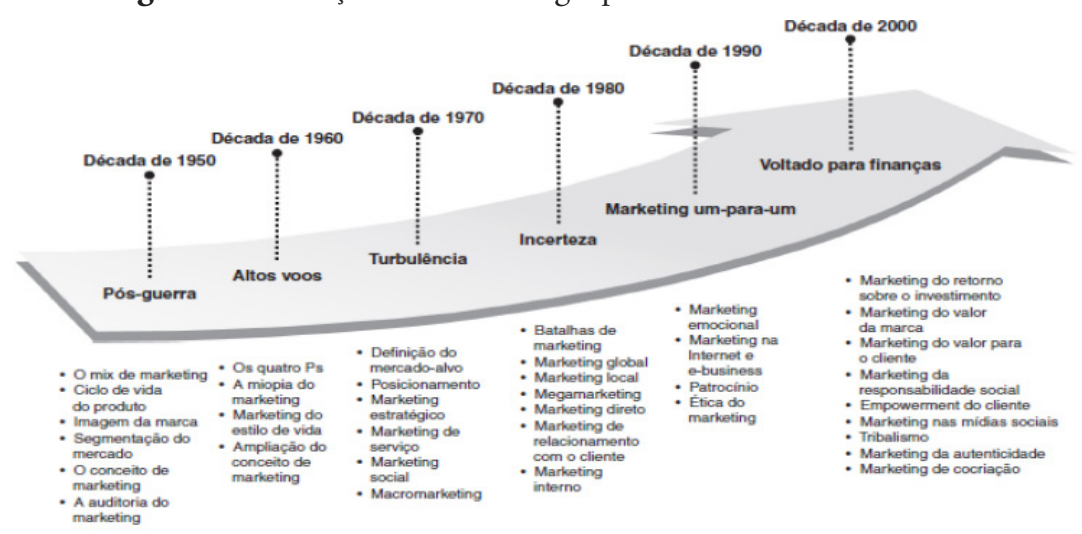

Fonte: Kotler, Kartajaya e Setiawan (2010, p.32).

Com base na Figura 2, demarca-se que antes de 1950 o marketing estava na era chamada de 1.0, que assim como no Fordismo tinha o objetivo de padronizar os produtos e eliminar desperdícios otimizando seus processos para poder oferecer um preço acessível ao maior número de pessoas possível, ou seja, centrava-se no produto. $\mathrm{O}$ marketing consistia em uma ferramenta clássica para ajudar a planejar o que oferecer e como oferecer aos consumidores. Basicamente, existiam os 4Ps: produto, preço, ponto de venda e promoção.

Com o acesso às informaçóes, o consumidor passou a ter a possibilidade de comparar preços, marcas e buscar os produtos que melhor atendiam suas necessidades. Foi entáo, que as pessoas deixaram de ser meros compradores para tornarem-se clientes e as empresas precisaram segmentar melhor seu públicoalvo, pois a fabricação em massa - com produtos básicos e genéricos - não mais os satisfazia, passando então para a era do marketing 2.0, cuja qualidade passou a ser vista também como uma área de investimento visando o diferencial, centrando-se então, no consumidor. Mais tarde, com o marketing 3.0, chegou-se na era onde fazia-se preciso reconhecer que o consumidor era mais do que um simples comprador, era alguém com preocupaçóes coletivas e ambientais e desejava fazer parte de uma sociedade melhor (Kotler, Kartajaya, \& Setiawan, 2010). Desse modo, o autor define três pilares da teoria 3.0: colaboração, cultura 
e espiritualidade. Tal modelo de marketing possui foco nos valores, entende o consumidor como ser humano, além de estar totalmente atrelado ao planejamento estratégico da empresa.

Atualmente, via marketing 4.0, Kotler, Kartajaya e Setiawan (2017) destaca que o esforço está em olhar para o marketing em uma dimensão diferente, abrangendo a conectividade e a tecnologia. O autor ainda acrescenta, que consiste em uma abordagem que combina interaçôes on-line e off-line entre empresas e clientes, mescla estilo com substância no desenvolvimento das marcas e, finalmente, complementa a conectividade máquina a máquina com o toque de uma pessoa, para fortalecer o engajamento dos consumidores. Gabriel (2010) conceitua o termo como o marketing que adota estratégias em algum componente digital no marketing mix - produto, preço, praça ou promoção. Diante do exposto, apresentase o Quadro 1, a fim de demarcar suas fases.

Quadro 1 - Evolução do marketing

\begin{tabular}{|c|l|}
\hline Ano/Fase & \multicolumn{1}{c|}{ Descrição } \\
\hline $\begin{array}{c}1900 \\
\text { Marketing 1.0 }\end{array}$ & Centrado no produto, evidenciando somente os aspectos tangíveis. \\
$\begin{array}{c}1950 \\
\text { Marketing 2.0 }\end{array}$ & Centrado no consumidor e em suas satisfaçóes também emocionais \\
\hline $\begin{array}{c}\text { Marketing 3.0 } \\
\text { 1980 - atual } \\
\text { Marketing 4.0 }\end{array}$ & $\begin{array}{l}\text { Centrado no ser humano (satisfazer todos seus anseios), cuja lucratividade tem como } \\
\text { contrapeso a responsabilidade corporativa. }\end{array}$ \\
\hline centrado totalmente na internet e na geração de conteúdo com objetivo de atrair clientes \\
\hline
\end{tabular}

Fonte: Elaborado pelas autoras com base em Kotler, Kartajaya e Setiawan (2010; 2017).

$\mathrm{Na}$ contemporaneidade, a fase atual em que se encontra o marketing é a 4.0, em que os mercados consumidores e empresariais, estão adaptando-se as mudanças digitais e reconhecendo a fundamental importância do digital para que continuem estes continuem ativos e atuantes sem limitarem-se a mera obsolescência. Desse modo, com o entendimento prévio sobre cada fase da evolução do marketing, verifica-se a relevância de retratar as diferenças entre o marketing tradicional e o digital (4.0), visando uma compreensão integralizada, para isso apresenta-se a Figura 3.

Figura 3 - Marketing tradicional x marketing digital

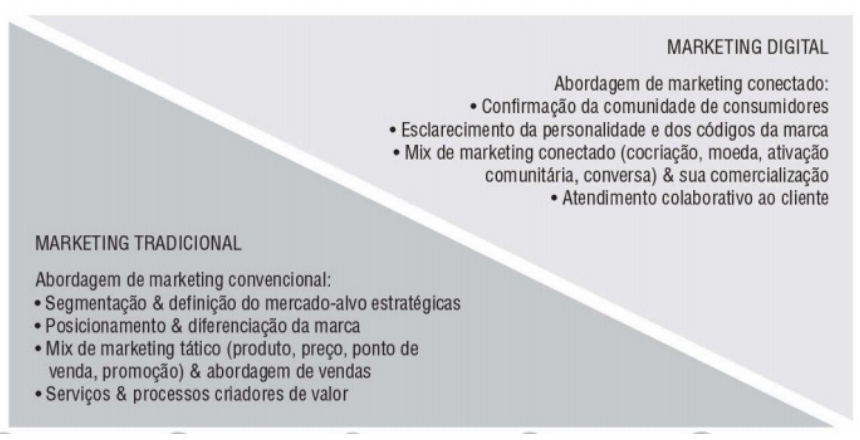

Fonte: Kotler, Kartajaya e Setiawan (2017).

Observa-se na Figura 3, que grandes foram as alteraçóes, a qual passou do foco do produto para o digital. Kotler, Kartajaya e Setiawan (2017) referem que o marketing digital e o marketing tradicional devem coexistir no marketing 4.0 com o objetivo máximo de conquistar a defesa da marca pelos clientes. 
Assim, pode-se afirmar que as perspectivas teóricas abordadas neste trabalho foram importantes para desenvolvimento das teorias do marketing, uma vez que foram evoluindo conforme as mudanças e contingências estabelecidas pelos mercados e nos ambientes externos e internos.

\subsection{Marketing estratégico ou estratégias de marketing}

Historicamente a estratégia está ligada à antecipação de cenários e planos de ação (Schnaars, 1991). Jamais existiu uma definição única, definitiva de estratégia. O termo já teve vários significados, diferentes em sua amplitude e complexidade (Camargos \& Dias, 2003). Sendo assim, apresenta-se no Quadro 2 algumas definições da estratégia no contexto organizacional, de acordo com a visão de alguns autores.

Quadro 2 - Definiçóes de estratégia organizacional

\begin{tabular}{|c|c|}
\hline Autores & Definição \\
\hline $\begin{array}{l}\text { Von Neumann e Morgenstern } \\
\text { (1947) }\end{array}$ & $\begin{array}{l}\text { Estratégia é uma série de ações realizadas por uma empresa conforme uma situação } \\
\text { em particular. }\end{array}$ \\
\hline Drucker (1954) & $\begin{array}{l}\text { Estratégia é a análise de situação atual e de mudanças se necessárias. Incorpora-se a } \\
\text { esta análise os recursos disponíveis e os que precisam ser adquiridos. }\end{array}$ \\
\hline Chandler (1962) & $\begin{array}{l}\text { Estratégia é a fixação de objetivos básicos de longo prazo de uma empresa e a adoção } \\
\text { de açōes adequadas e recursos para atingir esses objetivos. }\end{array}$ \\
\hline Ansoff (1965) & $\begin{array}{l}\text { Estratégia é um conjunto de decisóes determinadas pelo mercado do produto a } \\
\text { comercializar, crescimento objetivado, vantagens competitivas da organizaçáo e } \\
\text { sinergia organizacional. }\end{array}$ \\
\hline Mintzberg (1967) & $\begin{array}{l}\text { Estratégia é a soma das decisóes tomadas por uma organização em todos os aspectos, } \\
\text { tanto comerciais como estruturais, sendo que a estratégia evolui de acordo com o } \\
\text { processo de aprendizado do gestor da firma. }\end{array}$ \\
\hline Cannon (1968) & $\begin{array}{l}\text { Estratégias são as decisóes voltadas à realização de açóes direcionadas, que são } \\
\text { requeridas para que a empresa seja competitiva e alcance os seus objetivos. }\end{array}$ \\
\hline Lodi (1969) & $\begin{array}{l}\text { Estratégia é a mobilização de todos os recursos da empresa no âmbito nacional ou } \\
\text { internacional visando atingir objetivos a longo prazo. Seu objetivo é permitir maior } \\
\text { flexibilidade de resposta às contingências imprevisíveis. }\end{array}$ \\
\hline Newman e Logan (1971) & $\begin{array}{l}\text { Estratégias são planos que veem o futuro e antecipam mudanças. Oferecem açóes que } \\
\text { levam a vantagens competitivas para aproveitar uma ou mais oportunidades, e são } \\
\text { integradas na missão da organização. }\end{array}$ \\
\hline Schendel e Hatten (1972) & $\begin{array}{l}\text { Estratégia é definida como os objetivos básicos da organização, as diretrizes para } \\
\text { orientar as açóes e atingir estes objetivos, e a alocação de recursos para a organização } \\
\text { se relacionar com seu ambiente. }\end{array}$ \\
\hline $\begin{array}{l}\text { Uyterhoeven, Ackerman e } \\
\text { Rosenblun (1973) }\end{array}$ & $\begin{array}{l}\text { Estratégia é prover direção e coesão na empresa, e é composta por diversos passos: } \\
\text { identificar os vários perfis estratégicos, realizar uma previsão estratégica, auditar os } \\
\text { recursos disponíveis, avaliar as alternativas de possíveis estratégias, testar a consistência } \\
\text { das estratégias potenciais, realizar a escolha da estratégia a seguir. }\end{array}$ \\
\hline Ackoff (1974) & $\begin{array}{l}\text { Estratégia é ligada aos objetivos de longo prazo e os caminhos para conquistá-los, e } \\
\text { que afetam toda a organização. }\end{array}$ \\
\hline $\begin{array}{l}\text { McCarthy, Minichello e Curran } \\
\text { (1975) }\end{array}$ & $\begin{array}{l}\text { Estratégia é uma análise do ambiente onde está a organização, e seleção de } \\
\text { alternativas que irão orientar os recursos e objetivos da organização, conforme o risco } \\
\text { e possibilidades de lucros, e viabilidade que cada alternativa oferece. }\end{array}$ \\
\hline Glueck (1976) & $\begin{array}{l}\text { Estratégia é um plano de unificação, compreensão e integração da empresa, desenhado } \\
\text { para assegurar que os objetivos da organização serão alcançados. }\end{array}$ \\
\hline
\end{tabular}




\begin{tabular}{|c|c|}
\hline McNichols (1977) & $\begin{array}{l}\text { Estratégia está inserida em uma formulação de políticas: ela contém uma série de } \\
\text { decisóes que refletem os objetivos básicos do negócio da organização, e como utilizar } \\
\text { as capacidades e recursos internos para atingir estes objetivos. }\end{array}$ \\
\hline Mintzberg (1979) & $\begin{array}{l}\text { Estratégia é uma mediação de forças entre a organização e seu ambiente: estabelece } \\
\text { padrōes consistentes de decisōes organizacionais conforme o ambiente vivenciado. }\end{array}$ \\
\hline Bracker (1980) & $\begin{array}{l}\text { Estratégia tem duas características: uma análise situacional ou ambiental que } \\
\text { determina a posiçấo da empresa no mercado; o uso apropriado dos recursos da } \\
\text { empresa para alcançar os seus objetivos. }\end{array}$ \\
\hline Porter (1981) & $\begin{array}{l}\text { Estratégia é a escolha da firma de variáveis de decisão chave, como preço, promoçáo, } \\
\text { quantidade e qualidade. A empresa, para ter bom desempenho, deve se posicionar } \\
\text { corretamente na sua indústria. }\end{array}$ \\
\hline Mintzberg e McHugh (1985) & $\begin{array}{l}\text { Estratégia é um padrão em uma corrente de açôes ou decisóes. Desconsidera } \\
\text { possibilidades de diferentes estratégias para condiçoes ambientais diversas. }\end{array}$ \\
\hline Andrews (1991) & $\begin{array}{l}\text { Estratégia é o padrão de decisão em uma empresa que determina e revela seus } \\
\text { objetivos, propósitos ou metas. Ela produz as principais políticas e planos para a } \\
\text { obtençâa dos objetivos e metas. Define a escala de negócios em que a empresa deve } \\
\text { se envolver, o tipo de organizaçáo econômica e humana que pretende ser e a natureza } \\
\text { da contribuição econômica e não econômica que pretende proporcionar a seus } \\
\text { acionistas, funcionários e comunidades. }\end{array}$ \\
\hline Porter (1992) & $\begin{array}{l}\text { Estratégia é um conjunto de açóes ofensivas ou defensivas para criar uma posição } \\
\text { defensável numa indústria, para enfrentar com sucesso as forças competitivas e, } \\
\text { assim, obter um retorno maior sobre o investimento. }\end{array}$ \\
\hline Porter (1999) & $\begin{array}{l}\text { Estratégia significa desempenhar atividades diferentes das exercidas pelos rivais ou } \\
\text { desempenhar as mesmas atividades de maneira diferente. }\end{array}$ \\
\hline
\end{tabular}

Fonte: Elaborado pelas autoras com base em Mainardes, Ferreira e Tontini (2009).

Considerando as definiçóes citadas no Quadro 2, pode-se definir que o conceito de estratégia depende do ponto de vista de quem a vê, podendo mudar com o tempo e com muitos significados, desde os mais abrangentes aos mais detalhados. Essa multiplicidade de definiçóes torna a estratégia um conceito complexo e carregado de subjetividade (Mainardes, Ferreira \& Tontini, 2009).

O Marketing Estratégico tem como filosofia a orientação voltada para mercado com princípio de busca de geração de valores superiores para os clientes, focado na elaboração e implementação de estratégias para crescimento no nível corporativo assim como de crescimento e também do posicionamento de mercado sob o prisma do campo do domínio competitivo (Toledo, 2012).

As empresas, frequentemente, fazem investimentos em ações de marketing. Muitas vezes, esses investimentos estão voltados para objetivos estratégicos, planejados pela alta direção e colocados em prática pela linha de frente. Desse modo, o marketing estratégico é considerado como a análise, o planejamento, a implementaçáo e o controle de programas e/ou projetos formulados para propiciar trocas voluntárias de valores com o mercado-alvo, no propósito de atingir objetivos operacionais concretos (Toledo, 2018). Ou seja, o marketing estratégico implica na análise sistemática e constante das necessidades de mercado e desenvolvimento de conceitos e produtos, com bons desempenhos destinados a grupos de compradores exclusivos, que exibem qualidades distintas que os individualizam dos concorrentes imediatos, garantindo ao produtor uma vantagem competitiva duradoura e defensável (Lambin, 2000). O autor ainda destaca que a função do marketing estratégico é orientar a empresa para as oportunidades existentes ou criar oportunidades atrativas, que oferecem um potencial de crescimento e rentabilidade. A extensão temporal do marketing posiciona-se no médio prazo e longo prazo, e tem como objetivo especificar a missão 
da empresa, definir metas, preparar uma estratégia de desenvolvimento e vigiar a manutenção de uma estrutura equilibrada da gama de produtos.

Nesse entendimento, a Quadro 3 apresenta algumas especificidades do marketing estratégico.

Quadro 3 - Face do marketing estratégico

\begin{tabular}{|c|}
\hline $\begin{array}{c}\text { MARKETING ESTRATÉGICO } \\
\text { (Abordagem de Análise) }\end{array}$ \\
\hline Análise das necessidades: definição do mercado de referência \\
\hline Segmentação do mercado: macro e micro segmentação \\
\hline Análise da atratividade: mercado potencial, ciclo de vida \\
\hline Análise da competitividade: vantagem competitiva defensável \\
\hline Escolha de uma estratégia de desenvolvimento \\
\hline
\end{tabular}

Fonte: Lambin (2000)

Para Porter (1989) a vantagem competitiva surge essencialmente do valor que uma empresa consegue criar para seus compradores e que excede o custo de fabricação da empresa. A criação de valor para um produto ou serviço fornece a diferença entre a oferta das empresas. Assim, o valor pode ser criado como um serviço excepcional ou agregado, com características próprias, métodos de excelência em distribuição e componentes, como também matérias-primas de qualidade superior (Andersen \& Vincze, 2000). A cadeia de valor inclui as atividades que geram valor ao cliente, a qual revela formas de obtenção de vantagem competitiva pelas diversificas atividades primárias entre logística, operaçóes, marketing, vendas e serviços. As secundárias incluem compras, tecnologia, RH e a estrutura da firma (Porter, 1989).

Aliado a esse entendimento, delibera-se que as estratégias de marketing em geral baseiam-se nos estudos das variáveis controláveis e incontroláveis. As variáveis controláveis são aquelas passíveis de gerenciamento, que podem ser redimensionadas ou modificadas conforme as necessidades empresariais e as exigências do mercado, tais como: Políticas de Produto ou Serviços, Políticas de Preço, Políticas de Distribuição e Políticas de Comunicação. Já as variáveis incontroláveis se referem ao ambiente externo da empresa, como em forças macro e micro ambientais que não podem ser gerenciadas por uma empresa, pois são forças externas que influenciam as açóes de marketing e de todos os competidores do mercado (Mintzberg, Ahlstrand \& Lampel, 2000; Hooley, Piercy \& Nicoulaud, 2011). Saunders e Hooley (1996) expressam que a essência do desenvolvimento de uma estratégia de marketing para uma empresa está em assegurar que suas competências sejam compatíveis com o ambiente competitivo, no negócio em que opera, não apenas hoje como também no futuro previsível. Desse modo a consignação de uma estratégia de marketing efetiva começa com uma avaliação minuciosa das capacidades da empresa em relação à concorrência, bem como as oportunidades e ameaças exibidas pelo ambiente e identificadas no mercado de referência, identificando a vantagem competitiva da empresa, as metas com respeito à concorrência e as bases do posicionamento competitivo da organização (Valdés, 2003).

Dessa forma, faz-se necessário traçar as estratégias que serão seguidas. Day (1992) e He e Harris (2020) definem que as mudanças no cenário e no contexto de marketing forçaram as organizaçóes a desenvolver agilidade estratégica, como o desenvolvimento de atividades e a tomada de decisão a fim de construir e manter uma vantagem competitiva sustentável. Assim é possível responder as demandas externas do mercado, principalmente a voltada para o mercado consumidor. As estratégias auxiliam na entrega de 
valor aos mercados e na obtenção da vantagem competitiva (Woodruff, 1997). Ainda, Lambin (2000) destaca que o marketing estratégico é capaz de identificar as necessidades insatisfeitas ou mal satisfeitas de modo a desenvolver produtos novos adaptados a essas expectativas. Valdés (2003) adverte que nas últimas décadas um esforço acadêmico crescente está sendo empregado para desenvolver novos instrumentos de análises estratégicas, buscando contribuir para os processos de tomada de decisão da organização. Nessa conjuntura, o processo estratégico de marketing assentou-se sobre vários conceitos inter-relacionados, cuja base era o desenvolvimento de instrumentos que toleravam à empresa na configuração e manutenção da vantagem competitiva.

\subsection{Agenda de pesquisa}

Tomando como base os artigos selecionados e que integram esta pesquisa, realizou-se uma sintetização das sugestôes de estudos futuros propostos pelos mesmos, no sentido de organização de uma agenda de pesquisa das principais linhas de pesquisa trabalhadas dentro da área de marketing (Quadro 4). Inicialmente para escolha dos artigos que integram esta pesquisa foram realizadas buscas nas bases de dados internacionais (Web of Sience, Sience Direct e Scopus) no período 2013 a junho de 2018. Os trabalhos selecionados, atenderam aos seguintes critérios: objetivo proposto - o qual era de apresentar a evolução das perspectivas do marketing ao longo do tempo em especial a abordagem do marketing estratégico; últimos cinco anos de pesquisas sobre os referentes temas e; somente publicaçóes em revistas científicas. Posterior essa etapa de pesquisa, análise e seleção de trabalhos, os estudos foram lidos na integra e uma agenda de estudos foi sintetizada

Quadro 4 - Perspectivas teóricas e sugestão de estudos futuros

\begin{tabular}{|c|c|c|}
\hline Teoria & Agenda de pesquisa proposta & Autores \\
\hline $\begin{array}{l}\text { Marketing } \\
\text { transacional }\end{array}$ & $\begin{array}{l}\text {-A utilização do marketing transacional como estratégia para sites informativos } \\
\text { entre fabricante e fornecedor. -Analisar os meios de comunicaçáo eficaz para } \\
\text { franqueados e franquias. } \\
\text {-Analisar a importância da comunicação B2B no comércio do turismo. } \\
\text {-Revisão bibliométrica referente ao percurso do marketing transacional para o } \\
\text { marketing relacional. }\end{array}$ & $\begin{array}{c}\text { Karray \& Sigué } \\
\text { (2018); Khairol } \\
\text { (2016); Oromendía, } \\
\text { Paz, \& Rufín (2016); } \\
\text { Demo, Fogaça, Ponte, } \\
\text { Fernandes, \& Cardoso } \\
\text { (2015). }\end{array}$ \\
\hline $\begin{array}{l}\text { Orientação para o } \\
\text { mercado }\end{array}$ & $\begin{array}{l}\text {-Avaliar a aplicabilidade da teoria de OM e testar as relaçóes examinadas em } \\
\text { outros contextos internacionais; -Explorar diferentes medidas para avaliar } \\
\text { capacidade tecnológica; } \\
\text {-Examinar como a diversificaçáo internacional promove outras capacidades } \\
\text { organizacionais, como habilidades de marketing, capacidade gerencial e } \\
\text { capacidades operacionais; -Examinar outros aspectos do desempenho de novos } \\
\text { produtos, como a qualidade de novos produtos e a capacidade de inovação } \\
\text { do processo de desenvolvimento de novos produtos. -A aplicabilidade do } \\
\text { conceito de OM nos países em desenvolvimento. }\end{array}$ & $\begin{array}{l}\text { Wu, Ma, \& Liu } \\
\text { (2019); Guo, } \\
\text { Kulviwat, Zhu, \& } \\
\text { Wang (2019). }\end{array}$ \\
\hline
\end{tabular}




\begin{tabular}{|c|c|c|}
\hline $\begin{array}{l}\text { Marketing de } \\
\text { relacionamento }\end{array}$ & $\begin{array}{l}\text {-Estudos relacionados ao papel dos boundary spanners em mudanças culturais; } \\
\text {-Investigar o lado negro da cultura organizacional; -Analisar os processos e } \\
\text { mecanismos que explicam a decisáo de adotar um programa de fidelidade; } \\
\text {-Observar como as mudanças no status afetam a motivação dos clientes (ou } \\
\text { criam emoçóes negativas) para progredir nas hierarquias do programa ou como } \\
\text { o status influencia a satisfaçáo e a lealdade para com o programa e a empresa; } \\
\text {-Analisar o marketing de relacionamento B2B como influenciador de } \\
\text { crescimento nas economias emergentes. }\end{array}$ & $\begin{array}{l}\text { Larentis, Antonello, } \\
\text { \& Slongo (2018); } \\
\text { Viswanathan, Sese, \& } \\
\text { Krafft (2017); Ndubisi } \\
\text { \& Nataraajan (2016). }\end{array}$ \\
\hline $\begin{array}{l}\text { Mercados } \\
\text { consumidores }\end{array}$ & $\begin{array}{l}\text { Avaliar a embalagem como fator decisor e influenciador do consumidor no } \\
\text { contexto do layout e estética; - Realizaçáo de pequisa que use a orientação } \\
\text { sexual em vez de apenas o gênero como uma variável de segmentação dos } \\
\text { consumidores de produtos orgânicos. }\end{array}$ & $\begin{array}{l}\text { Moura (2018); Sultan, } \\
\text { Wong, \& Sigala } \\
\quad(2018)\end{array}$ \\
\hline $\begin{array}{l}\text { Mercados } \\
\text { organizacionais }\end{array}$ & $\begin{array}{l}\text {-Aprofundar e aprender sobre novos conceitos, como análise de dados e } \\
\text { business intelligence, experiência do cliente e educação do cliente. - Criação } \\
\text { de um modelo exploratório do de recuperação de serviços. - Proposição } \\
\text { de um modelo teórico capaz de predizer a intenção de recompra de PMEs } \\
\text { consumidoras de serviços logísticos, tendo como antecessor a satisfação, e } \\
\text { desta, o valor percebido. }\end{array}$ & $\begin{array}{l}\text { Lilien (2016); Cortez } \\
\text { \& Johnston (2017); } \\
\text { Johnston \& Cortez } \\
\text { (2018). }\end{array}$ \\
\hline Customer Equity & $\begin{array}{l}\text { - Utilizar o cálculo da métrica CLV a inquisição de custos margem e a } \\
\text { receita total; -Abranger diferentes tipos de lojas de varejo, como loja de } \\
\text { departamento ou loja de conveniência para explorar o nível de apego } \\
\text { emocional ou compromisso dos clientes, o que ajuda a promover a longo } \\
\text { prazo relacionamento sustentável. }\end{array}$ & $\begin{array}{l}\text { Moliner \& Tena } \\
\text { (2016); Yoon \& Oh } \\
\text { (2016). }\end{array}$ \\
\hline Valores & $\begin{array}{l}\text {-Validação e análise da relação que os valores pessoais típicos da cultura } \\
\text { brasileira, representam ao ser nseridos na relaçáo estrutural entre os diferentes } \\
\text { valores e dimensóes que compóe esta teoria; -Utilização da escala RVS } \\
\text { completa (valores instrumentais e valores terminais) ou outras escalas de } \\
\text { valores validadas, como Values and Life Style (VALS), List of Values (LOV), } \\
\text { para comparar o papel moderador dos valores na relação atitude/fases da } \\
\text { lealdade; -Pesquisa que integre variáveis mediadoras e moderadoras entre } \\
\text { valores e comportamento, bem como variáveis do contexto organizacional. }\end{array}$ & $\begin{array}{l}\text { Henrique, Monteiro, } \\
\text { \& Matos (2013); } \\
\text { Kamia \& Porto } \\
\text { (2011). }\end{array}$ \\
\hline $\begin{array}{l}\text { Satisfação, } \\
\text { Recomendação e } \\
\text { Recompra }\end{array}$ & $\begin{array}{l}\text { Estudos que visem a busca da compreensão da satisfação na literatura de } \\
\text { marketing de serviços; - Aprofundar o conhecimento acerca dos construtos } \\
\text { antecedentes da intençáo de recompra. }\end{array}$ & $\begin{array}{l}\text { Wirtz \& Zeithaml } \\
\text { (2018); Milan, et al. } \\
\text { (2017). }\end{array}$ \\
\hline
\end{tabular}

Fonte: Elaborada pelas autoras (2020).

Dessa forma, fica evidenciada que ainda se encontram lacunas na literatura e que precisam ser investigadas, uma vez que o recorte temporal se deu até junho de 2018, e muitas foram as alteraçôes ocorridas no campo do marketing, sobretudo com o advento da pandemia da Covid-19.

Além do exposto no Quadro 4, pode-se consultar a agenda de estudos futuros, elaborada pelo Marketing Sience Institute (MSI). Essa agenda fornece uma previsão dos principais tópicos de pesquisa a serem estudados no decorrer dos anos. Desse modo, evidencia-se a relevância do marketing para as organizaçôes, que de forma integrada às demais áreas podem trazer resultados positivo, significativos e que impactem na competitividade organizacional.

\section{Considerações finais}

O sucesso de uma organização depende de sua habilidade em obter vantagens competitivas, tornando-as mais duradouras possíveis. Essas vantagens advêm em geral do desempenho da organização 
em dois quesitos: primeiro, da obtenção do menor custo operacional, que comporte a prática de preços competitivos a um volume lucrativo de vendas, permitindo uma participação de mercado auspiciosa. Em segundo lugar, advêm da estratégia (marketing), visando à aquisição de elevados padróes de qualidade dos produtos e serviços, diferenciando-os da concorrência

Desse modo, este ensaio teórico teve como objetivo sintetizar os conceitos referentes à evolução das perspectivas teóricas do marketing e suas principais contribuiçóes ao longo do tempo, como ressaltar a importância do marketing estratégico para as organizaçóes. A pesquisa realizada, permitiu conhecer e compreender as concepçóes teóricas do marketing e seu desenvolvimento ao logo do tempo. As constataçóes alçadas possuem importantes contribuiçóes. Uma de suas principais, está na identificação da cultura, que pode estar vinculada à formação da estratégia como um processo de interação social, onde estão arraigados os valores e as crenças da organização, que são compartilhados por seus membros. A cultura é a filosofia da organização é o que ela transmite as pessoas.

Do mesmo modo, outra contribuição importante é apresentada no Quadro 2. Nele, as sugestôes de estudos futuros são evidenciadas. Ainda, cabe ressaltar que há muito para acrescentar e evoluir principalmente no que diz respeito às teorias do marketing, mas principalmente na integração com outras áreas, para que de fato seja colocado em prática o marketing estratégico visando um objetivo maior, e assim alcançar resultados e benefícios mais vantajosos para a organização. No decorrer da pesquisa percebeu-se essa carência, e levanta-se como necessário a integração do marketing nas diferentes áreas da empresa, como na produção, comercial, vendas, custos e etc. Dessa forma a empresa pode obter um desempenho acima da média e buscar uma posição competitiva sustentável no mercado.

Com a revisão teórica realizada, espera-se ter apresentado um breve panorama do desenvolvimento do Marketing como uma área do conhecimento distinta, bem como ter delineado o contexto no qual se deu esse desenvolvimento. Além disso, espera-se que esse estudo possa ajudar a entender alguns aspectos do Marketing na atualidade, bem como contribuir para seu desenvolvimento.

Por fim, cabe ressaltar as limitaçóes da pesquisa, destacando-se que a mesma focou na evolução das perspectivas do marketing e suas estratégias, em detrimento de outros aspectos, a exemplo do marketing voltado para causas sociais, capacidades interfuncionais ou dinâmicas, o que pode se constituir numa sugestão para pesquisas futuras, a ampliação desse campo histórico. Também se entende como pertinente identificar e avaliar as estratégias de marketing no cenário atual da pandemia, uma vez que grandes alteraçôes no modo de trabalhar e de consumir foram introduzidas.

\section{Referências}

Ackoff, R. L. (1974). Redesigning the future: Systems Approach to Societal Problems. New York. Hardcover.

AMA - American Marketing Association (1985). AMA Board approves new marketing definition. News, 9(5).

AMA - American Marketing Association. (2017). Definition of Marketing. Recuperado de https://www. ama.org/the-definition-of-marketing-what-is-marketing/ 
Ambler, T. (2004). The new dominant logic of Marketing: views of the elephant. London: Centre for Marketing of London Business School (No. 04-903). Working Paper.

Andersen C. H. \& Vincze, J.W. (2000). Strategic Marketing Management. Houghton Mifflin Company.

Andrews, K. R. (1991). The concept of corporate strategy (2a ed.). In Mintzberg, H.; Quinn, J. B. (org.). The strategy process, concepts, contexts, cases. New Jersey: Prentice-Hall.

Ansoff, I. (1965). The Corporate Strategy. McGraw Hill.

Antunes, J., \& Rita, P. (2008). O marketing relacional como novo paradigma: uma análise conceptual. Revista de Gestão dos Países de Língua Portuguesa, 7(2), 36-46.

Bagozzi, R. P. (1995). Reflections on relationship marketing in consumer markets. Journal of the Academy of Marketing science, 23(4), 272-277.

Barakat, L. L., Lara, J. E., \& Gosling, M. (2011). O surgimento da escola de pensamento do marketing de relacionamento e seus fundamentos. Revista Pretexto, 12(3), 29-46.

Berry, L. L. (1983). Relationship marketing. Emerging perspectives on services marketing, 66(3), 33-47.

Bitner, M. J. (1995). Building service relationships: it's all about promises. Journal of the Academy of marketing science, 23(4), 246-251.

Blattberg, R. C., \& Deighton, J. (1996) Manage marketing by the customer equity test. Harvard Business Review, 74 (4), 136-144.

Bracker, J. (1980). The historical development of the strategic management concept. The Academy of Management Review, 5(2), 219- 224.

Camargos, M. A. D., \& Dias, A. T. (2003). Estratégia, administração estratégica e estratégia corporativa: uma síntese teórica. REGE Revista de Gestão, 10(1), 27-39.

Cannon, J. T. (1968). Business strategy and policy. New York: Harcourt, Brace e World.

Chandler, A. D. (1962). Strategy and Structure: Chapters in the History of the American Industrial Enterprise. Cambridge: Massachusetts Institute of Technology Press.

Christopher, M.; Payne, A. E Ballantine, D. (2004), Relationship Marketing (2a ed.). ButterworthHeinemann.

Churchill, G. A. JR., \& Peter. J. P. (2005). Marketing: Criando valor para os clientes (2a ed). São Paulo: Saraiva.

Cortez, R. M., \& Johnston, W. J. (2017). The future of B2B marketing theory: A historical and prospective analysis. Industrial Marketing Management, 66, 90-102. 
Day, G. S. (1992). Marketing's contribution to the strategy dialogue. Journal of the Academy of marketing Science, 20(4), 323-329.

Day, G. S., \& Montgomery, D. B. (1999). Charting new directions for marketing. Journal of marketing, 63(4), 3-13.

Demo, G., Fogaça, N., Ponte, V., Fernandes, T., \& Cardoso, H. (2015). Marketing de relaciones (crm): estado del arte, revisión bibliométrica de la producción nacional de primera línea, institucionalización de la investigación en brasil y programa de investigación. RAM. Revista de Administração Mackenzie, 16(5), 127-160.

Deshpandé, R., Farley, J. U., \& Webster Jr, F. E. (1993). Corporate culture, customer orientation, and innovativeness in Japanese firms: a quadrad analysis. Journal of marketing, 57(1), 23-37.

Drucker, P. F. (1954). The practice of management. New York: Harper \& Brothers.

Drucker, P. F. (2011). Inovação e espirito empreendedor (entrepreneurship): prática e princípios. São Paulo: Cengage Learning.

Englert, N. F., Frio, R. S., Saldanha, C. S. V., \& Rossi, C. A. V. (2018). Reducao do escopo ou ampliacao da pratica? As perspectivas do marketing na visao de seus academicos. REAd. Revista Eletrônica de Administração, 24(2), 167-188.

Felton, A. P. (1959). Making the marketing concept work. Harvard business review, 37, 55-65.

Gabriel, M. (2010). Marketing na era digital. São Paulo: Novatec.

Glueck, W. F. (1976). Business policy: Strategy formation and management action. McGraw Hill: New York.

Grinberg, C., \& Luce, F. (2000, setembro). Marketing metrics - um novo desafio para a disciplina de marketing. Anais do Encontro Anual da Associação Nacional de Pós-Graduação e Pesquisa em Administração, Florianópolis, SC, Brasil, 24.

Gronröos, C. (1990). Relationship approach to marketing in service contexts: the marketing and organizational behaviour interface. Journal of Business Research, 20(1).

Gruen, T. (1995). The Outcome Set of Relationship Marketing in Consumer Markets. International Business Review, 4(4), 447-469.

Guo, C., Kulviwat, S., Zhu, J., \& Wang, Y. J. (2019). Competing in an emerging market: Antecedents and consequences of market orientation and the role of environmental factors. Journal of Strategic Marketing, 27(3), 248-267.

Gupta, S., Lehmann, D. R., \& Stuart, J. A. (2004). Valuing customers. Journal of Marketing Research, 16(1), 7-18.

Hakansson, H. (1982). International Marketing and Purchasing of Industrial Goods: An Interaction Approach. Chichester: John Wiley \& Sons. 
He, H., \& Harris, L. (2020). The Impact of Covid-19 Pandemic on Corporate Social Responsibility and Marketing Philosophy. Journal of Business Research, 116, 176-182.

Henrique, J. L., Monteiro, P. R. R., \& Matos, C. A. de (2013). As influências dos valores pessoais nas atitudes e nas fases da lealdade. Revista de ciências da administração, 15(36), 101-116.

Hooley, G. J., Piercy, N. F., \& Nicoulaud, B. (2011). Marketing Strategy and Competitive Positioning (4a ed.). Pearson/Prentice Hall.

Hunt, S. D., Arnett, D. B., \& Madhavaram, S. (2006). The explanatory foundations of relationship marketing theory. Journal of business \& industrial marketing, 21(2), 72-87.

Jaworski, B. J., Macinnis, D. J., \& Kohli, A. K. (2002). Generating competitive intelligence in organizations. Journal of market-focused management, 5(4), 279-307.

Johnston, W. J., \& Cortez, R. M. (2018). Unit pricing and its implications for B2B marketing research. Industrial Marketing Management, 69, 32-39.

Joshi. J, M., \& Dumbre, G. M. (2017). Basic Concept of E-Commerce. International Research Journal of Multidisciplinary Studies, 3(3), 1-5.

Kamia, M., \& Porto, J. B. (2011). Comportamento proativo nas organizaçôes: o efeito dos valores pessoais. Psicologia: ciência e profissão, 31(3), 456-467.

Karray, S., \& Sigué, S. P. (2018). Informational and/or transactional websites: Strategic choices in a distribution channel. Electronic Commerce Research and Applications, 27, 11-22.

Kohli, A. K., \& Jaworski, B. J. (1990). Market orientation: the construct, research propositions, and managerial implications. Journal of marketing, 54(2), 1-18.

Korper, S., \& Ellis, j. (2000). The e-commerce book: building the e-empire. San Diego.

Kotler, P. (2000). Administração de Marketing: Análise, Planejamento, Implementação e Controle (10a ed.). São Paulo: Prentice Hall.

Kotler, P., Kartajaya, H. \& Setiawan, I. (2010). Marketing 3.0: as forças que estão definindo o novo marketing centrado no ser humano. Elsevier

Kotler, P., Kartajaya, H., Setiawan, I. (2017). Marketing 4.0: do tradicional ao digital. Rio de Janeiro: Sextante.

Kumar, N. (2004). Marketing como estratégia: uma orientaçâo inovadora e comprovada para o crescimento e a inovaçâo. Rio de Janeiro: Elsevier.

Lamb, C. W., Hair, J. H., \& McDaniel, C. (2008). Segmenting and targeting markets (10a ed.). New Jersey: Cengage Learning.

Lambin, J. J. (2000). Marketing Estratégico. Lisboa: McGraw Hill. 
Larentis, F., Antonello, C. S., \& Slongo, L. A. (2018). Cultura organizacional e marketing de relacionamento: uma perspectiva interorganizacional. Revista Brasileira de Gestão de Negócios, 20(1), 37 56.

Lilien, G. L. (2016). The B2B Knowledge Gap. International Journal of Research in Marketing, 33(3), $543-556$.

Lobuono, R., Gosling, M. de S., Gonçalves, C. A., \& Medeiros, S. A. (2016). Relaçóes entre dimensôes da experiência, satisfação, recomendação e intenção de retornar: a percepção de participantes de evento cultural resumo. Podium Sport, Leisure and Tourism Review, 5(2), 15-37.

Lodi, J. B. (1969). O risco da administração por objetivos. Revista de Administração de Empresas, 9(3), 29-42.

Lübeck, R. M., Santini, F. O., Camargo, M. E., \& Wanin, T. S. (2016). Análise de aspectos hedônicos e utilitários como preditores da recomendação e recompra do Natal Luz. Revista Brasileira de Pesquisa Em Turismo, 10(2), 330-350.

Macneil, I. R. (1978). Contracts: Adjustment of Long-Term Economic Relations Under Classical, NeoClassical, and Relational Contract Law, Northwestern University Law Review 72, 854-905.

Macneil, I. R. (1980). Power, Contract, and the Economic Model, Journal of Economic Issues, 14(4), 909-923.

Mainardes, E. W., Ferreira, J. J. M., \& Tontini, G. (2009). O Entendimento Do Conceito De Estratégia E De Gestão Estratégica Dos Formandos Em Administração. Revista ANGRAD, 10(4), 55-82.

Mangini, E. R., Urdan, A. T., \& Santos, A. (2017). Da Qualidade em Serviços à Lealdade: Perspectiva Teórica do Comportamento do Consumidor. Revista Brasileira de Marketing. 16(2), 207-217.

McCarthy, D. J., Minichiello, R. J., \& Curran, J. R. (1975). Business policy and strategy: Concepts and readings. Homewood/Illinois: Irwin.

McCarthy, E. J. (1976). Marketing básico: uma visão gerencial. Rio de Janeiro: Zahar.

McNichols, T. J. (1977). Policy making and executive action (5a ed.). New York, McGraw-Hill.

Milan, G. S., Lima, V. Z. D., Eberle, L., \& De Toni, D. (2017). Los antecedentes de la intención de recompra de una marca de smartphones. REAd. Revista Eletrônica de Administração, 23(3), 147-172.

Mintzberg, H. (1967). The science of strategymaking. Industrial Management Review, 8(2), 71-81.

Mintzberg, H. (1979). The structuring of organizations. Englewood Cliffs/New Jersey: Prentice-Hall.

Mintzberg, H., \& McHugh, A. (1985). Strategy formation in an adhocracy. Administrative science quarterly, 160-197.

Mintzberg, H., Ahlstrand, B., \& Lampel, J. (2000). Safári de estratégia: um roteiro pela selva do planejamento estratégico. Porto Alegre: Bookman. 
Moliner, J. R. S., Tena, M. A.M. (2016). Customer equity and CLV in Spanish telecommunication services. Journal of Business Research, 69(10), 4694-4705.

Moreno, R. B., Rodrigues, G. P., Cantaleano, K. R., Kava, L. \& Martins, T. S. (2016, maio). Orientação para o Mercado: uma Análise de Cocitação das Publicaçôes no Período de 2010 a 2015. In: Anais do Encontro Anual do encontro de Marketing da Associação Nacional de Pós-Graduação e Pesquisa em Administração, Belo Horizonte, MG, Brasil.

Moretti, S. L. A. do., Oliveira, S. L. I., \& Souza, C. G. de (2018). A evolução do conceito de marketing e sua aplicação no turismo: simetrias evolutivas, assimetrias temporais. Revista de Turismo Contemporâneo, 6(1).

Moura, R. G. de (2018). Comportamento do consumidor: A influência da embalagem no processo de decisão de compra das mulheres na aquisição de cosméticos nos supermercados. REA-Revista Eletrônica de Administração, 16(1), 4-24.

MSI Workshop/Conference On Marketing Metrics. (1999). Swissôtel Washington The Watergate. Five Parallel Small Group Working, Washington.

Narver, J. C., \& Slater, S. F. (1990). The effect of a market orientation on business profitability. Journal of marketing, 54(4), 20-35.

Ndubisi, N. O., \& Nataraajan, R. (2016). Marketing relationships in the new millennium B2B sector. Psychology \& Marketing, 33(4), 227-231.

Nevin, J. R. (1995). Relationship marketing and distribution channels: Exploring fundamental issues. Journal of the Academy of marketing Science, 23(4), 327-334.

Newman, W. H., \& Logan, J. P. (1971). Strategy, policy and central management. Cincinatti: SouthWestern Publishing.

O’Malley, L., \& Tynan, C. (2000). Relationship Marketing in Consumer Markets - Rhetoric or Reality? European Journal of Marketing, 34(7), 797-815.

Oliver, R. L. (1997). Satisfaction: a behavioral perspective on the consumer. New York: McGraw Hill.

Oromendía, A. R.; Paz, M. D. R; Rufín, R. (2015). Research note: Relationship versus transactional marketing in travel and tourism trade shows. Tourism Economics, 21(2), 427-434.

Peterson, R. A. (1995). Relationship marketing and the consumer. Journal of the academy of marketing science, 23(4), 278-281.

Porter, M. E. (1981). The contributions of industrial organization to strategic management. Academy of management review, 6(4), 609-620.

Porter, M. E. (1989). A vantagem competitiva das naçôes (5a ed.). Rio de Janeiro: Campus. 
Porter, M. E. (1992). Vantagem Competitiva: criando e sustentando um desempenho superior (7a ed.). Campus, RJ. 512p.

Porter, M. E. (1999). Competição: Estratégias Competitivas Essenciais (9a ed.). Rio de Janeiro.

Rocha, A.; Christensen, C. (1999) O conceito de Marketing. In Rocha, A.; Christensen, C. Marketing: Teoria e Prática no Brasil. São Paulo: Atlas.

Rokeach, M. (1973). The nature of human values. New York: Free press.

Saunders, J., \& Hooley, G.J. (1996) Posicionamento Competitivo. EUA: Makron Books.

Schendel, D. E., \& Hatten, K. J. (1972). Business policy or strategic management. In: Mitchell, F. H. (org,). Academy of Management Proccedings. Boston: Little Brown, 56-72.

Schnaars, S.P. (1991). Marketing strategy: a customer-driven approach. New York: Free Press.

Schwartz, S. (2006). A theory of cultural value orientations: Explication and applications. Comparative sociology, 5(2-3), 137-182.

Schwartz, S. H. (1992). Universals in the content and structure of values: Theoretical advances and empirical tests in 20 countries. Advances in Experimental Social Psychology, 25(1), 1-65.

Schwartz, S. H. (1994). Beyond individualism/collectivism: New cultural dimensions of values. In U. Kim, H. C. Triandis, Ç. Kâğitçibaşi, S.-C. Choi, \& G. Yoon (Eds.), Cross-cultural research and methodology series, Vol. 18. Individualism and collectivism: Theory, method, and applications (p. 85-119). Sage Publications, Inc.

Schwartz, S. H., Melech, G., Lehmann, A., Burgess, S., Harris, M., \& Owens, V. (2001). Extending the cross-cultural validity of the theory of basic human values with a different method of measurement. Journal of cross-cultural psychology, 32(5), 519-542.

Sheth, J. N., \& Parvatiyar, A. (1995). The evolution of relationship marketing. International business review, 4(4), 397-418.

Sheth, J. N., Gardner, D. M., \& Garrett, D. E. (1988). Marketing Theory: Evolution and Evaluation. Jhon Wiley \& Sons.

Simões, R. (1976). Marketing Básico. São Paulo: Saraiva.

Sparemberger, A., \& Zamberlan, L. (2008). Marketing estratégico. Ijuí: Unijuí.

Storbacka, K. (1994). The Nature of Customer Relationship Profitability: Analysis of Relationships and Customer Bases in Retail Banking. Helsinki: Swedish School of Economics and Business Administration.

Sultan, P., Wong, H. Y., \& Sigala, M. (2018). Segmenting the Australian organic food consumer market. Asia Pacific Journal of Marketing and Logistics, 30(1), 1-23. 
Toledo, G. L. (2012). Marketing Estratégico. In: OLIVEIRO, B. (Org). Gestão de Marketing. São Paulo: Pearson Education.

Toledo, L. A. (2018). Marketing estratégico: da teoria a prática empresarial no ramo de telecomunicação. Revista. Intelig. Compet., 8(1), 244-264.

Uyterhoeven, H., Ackerman, R., \& Rosenblum, J. W. (1973). Strategy and organization: Text and cases in general management. Homewood/Illinois: Irwin.

Valdés, J. A. (2003). Marketing estratégico e estratégia competitiva de empresas turísiticas: um estudo de caso da cadeia hoteleira Sol Meliá. Tese de doutorado, Faculdade de Economia, Administração e Contabilidade, FEA/USP, São Paulo, SP, Brasil.

Vargo, S. L., \& Lush, R. F. (2004). Evolving a services dominant logic. Journal of marketing, 68(1), 1-17.

Viswanathan, V., Sese, F. J., \& Krafft, M. (2017). Social influence in the adoption of a B2B loyalty program: The role of elite status members. International Journal of Research in Marketing, 34(4), 901-918.

Von Neumann, J., \& Morgenstern, O. (1947). Theory of games and economic behavior. (2nd rev. ed.). Princeton University Press.

Voss, G. B., \& Voss, Z. G. (1997). Implementing a relationship marketing program: a case study and managerial implications. Journal of Services Marketing, 15 (6), 278-298.

Webster, F. E. Jr. (1992). The changing role of marketing in the corporation. Journal of marketing, 56(4), 1-17.

Weitz, B. A., \& Jap, S. D. (1995). Relationship marketing and distribution channels. Journal of the academy of Marketing Science, 23(4), 305-320.

Wirtz, J., \& Zeithaml, V. (2018). Cost-effective service excellence. Journal of the Academy of Marketing Science, 46(1), 59-80.

Woodruff, R. B. (1997). Customer value: the next source for competitive advantage. Journal of the academy of marketing science, 25(2), 139-153.

Wu, J., Ma, Z., \& Liu, Z. (2019). The moderated mediating effect of international diversification, technological capability, and market orientation on emerging market firms' new product performance. Journal of Business Research, 99, 524-533.

Yoon, S., \& Oh, J. C. (2016). A cross-national validation of a new retail customer equity model. International Journal of Consumer Studies, 40(6), 652-664. 